\title{
LA GARANTÍA DE LOS DERECHOS HUMANOS DEL PACIENTE A TRAVÉS DEL DERECHO CONSTITUCIONAL, PROCESAL CONSTITUCIONAL Y EL DERECHO DE DAÑOS*
}

\author{
José López Oliva**
}

Fecha de recibido: febrero 12 de 2014.

Fecha de aprobado: agosto 1 de 2014.

Artículo de revisión

Forma de citación: López, J. (2014). La garantía de los derechos humanos del paciente a través del derecho constitucional, procesal constitucional y derecho de daños. Revista Prolegómenos. Derechos y Valores, 17, 34, 53-77.

\begin{abstract}
Resumen
Entre el prestador de salud y el usuario del servicio médico, se celebra un acto jurídico, donde se pueden presentar daños que vulneran los derechos del paciente. Dicho evento, genera perjuicios al usuario médico, producidos por negligencia del prestador del servicio en salud; con el objetivo de prevenir, sancionar o reparar las lesiones que se causan a la víctima, se instituyen acciones constitucionales y legales. Las acciones de tutela, grupo y cumplimiento y el derecho de daños, propenden por la garantía de los derechos a la verdad, la justicia y la reparación integral de los males que se suscitan por el evento adverso. El objetivo de la investigación es demostrar que a través de las acciones constitucionales y el derecho de daños, se garantizan los derechos del paciente. Demostración que se realiza mediante un estudio bibliográfico de revisión, utilizando el enfoque cualitativo.
\end{abstract}

\section{Palabras clave:}

Derechos del paciente, evento adverso, acciones constitucionales, derecho de daños, daños punitivos, reparación integral.

\footnotetext{
Este artículo, es un producto del proyecto de investigación denominado "La aplicación de la teoría de los daños punitivos en la responsabilidad médico-sanitaria en Colombia" (2013) desarrollado en la UMNG.

** Profesor e investigador, conferencista nacional e internacional, docente universitario de pregrado y posgrado. Docente investigador de la Universidad Militar Nueva Granada (UMNG). Director de la Línea de Investigación en Derecho de la Responsabilidad y de Seguros de la UMNG. Exdirector del Área de Derecho Privado. Magíster en Derecho de la Universidad de los Andes, magíster de la Universidad Carlos III de Madrid (España), especializado en Derecho Comercial de la Universidad Pontificia Bolivariana de Medellín y Derecho Penal y Probatorio de la Universidad del Rosario. Con estudios de doctorado en Derecho de la Universidad de Buenos Aires (Argentina); doctorando en Bioética Médica y Salud Pública de la UMNG. Docente certificado en el ámbito internacional por la Life Office Management Association, Inc. (Loma), con sede en Atlanta-Georgia (Estados Unidos). Tratadista y ensayista de textos de contenido sociojurídico. Correo electrónico: Jose.lopez@unimilitar.edu.co.
} 


\title{
THE GUARANTEE OF PATIENT'S HUMAN RIGHTS THROUGH CONSTITUTIONAL LAW, CONSTITUTIONAL PROCEDURE, AND TORT LAW
}

\begin{abstract}
Between the healthcare provider and the user of medical service, a legal procedure is concluded in which there may occur damages that vulnerate the patient's right. Such events are harmful to the user, due to the negligence of the healthcare provider; with the objective of preventing, penalizing or repairing the injuries caused to the victim, constitutional and legal actions are established. The protection, group and compliance actions, and the tort law, tend to guarantee the right to the truth, justice and integral reparation of the damages caused by the adverse event. The objective of the research is to demonstrate that through constitutional actions and the tort law, the patient's rights can be guaranteed. This demonstration can be done through a bibliographical study of revision, using the qualitative focusing.
\end{abstract}

\section{Key words:}

Patient's rights, adverse event, constitutional actions, tort law, punitive damages, integral reparation.

\section{A GARANTIA DOS DIREITOS HUMANOS DO PACIENTE A TRAVES DO DIREITO CONSTITUCIONAL, PROCESSUAL CONSTITUCIONAL E DIREITO DE DANOS}

\begin{abstract}
Resumo
Entre o prestador de saúde e o usuário do serviço médico, é celebrado um ato jurídico, onde podes se apresentar danos que vulneram os direitos do paciente. Dito evento, gera prejuízos ao usuário médico, produzidos por negligencia do prestador do serviço em saúde; com o objetivo de previr, sancionar ou reparar as lesões que são causadas à vítima, são instituídas ações constitucionais e legais. As ações de tutela, grupo e cumprimento e o direito de danos, propendem pela garantia dos direitos à verdade, à justiça e a reparação integral dos mais que são suscitados pelo evento adverso. O objetivo da investigação é demonstrar que a través das ações constitucionais e o direito de danos, são garantidos os direitos do paciente. Demonstração que é realizada mediante um estudo bibliográfico de revisão, utilizando o enfoque qualitativo.
\end{abstract}

\section{Palavras chave:}

Direitos do paciente, evento adverso, ações constitucionais, direito de danos, danos punitivos, reparação integral.

\section{INTRODUCCIÓN}

El derecho a la salud del usuario médico-sanitario en Colombia, es un derecho humano y a la vez fundamental. Este derecho se puede transgredir en la prestación del servicio sanitario, en el que intervienen el prestador del servicio médico y el paciente, a quien se le debe garantizar en un proceso judicial o extrajudicial, los derechos a la verdad, la justicia y la reparación integral por los daños generados por el citado prestador. En concordancia, el derecho constitucional, procesal constitucional y el derecho de daños, protegen a las víctimas de hechos médico-sanitarios que 
ocasionan perjuicios, por medio de normas constitucionales, legales y doctrinas que al aplicarse, buscan sancionar conductas reprochables ejecutadas por el victimario. La teoría de los daños punitivos, es una de las citadas doctrinas.

Las normas reglas, los principios y las teorías jurídicas, procuran la protección del paciente en su relación con el médico, donde se involucran derechos cardinales a la vida y a la integridad física y psíquica del usuario médico, potencial víctima en el contrato de prestación de servicios en salud. La jurisprudencia nacional y foránea, establecen que la víctima del hecho productor de un daño, el paciente en esta investigación, es la persona humana sobre quien recae directamente el perjuicio patrimonial o inmaterial.

El usuario del servicio en salud, espera que el prestador reduzca o elimine el dolor generado por la alteración de su organismo. Para lograr este objetivo, el sistema de salud integrado por el promotor, prestador y recurso humano en salud, requiere de herramientas médicas, uso de medicamentos, realización de diagnósticos médicos, con el propósito de cumplir con las obligaciones constitucionales y legales, que se dirigen a garantizar el derecho humano y fundamental a la salud del paciente.

Para garantizar este derecho, se necesita suministrar el derecho procesal constitucional y sustancial, así como también la incorporación de la teoría de los daños punitivos, con el objetivo de proteger al usuario de la prestación sanitaria, incluidos los niños, niñas y adolescentes. En este orden de ideas, para que se aseguren los derechos a la salud, la integridad física y mental y el derecho a la reparación integral de los perjuicios causados al paciente, se requiere de acciones constitucionales consagradas en la Carta Política colombiana.

Las acciones de tutela, de grupo y populares, entre otras, garantizan al paciente el acceso a la prestación del servicio de salud. Si esta prestación es inadecuada, o realizada de manera inoportuna e ineficaz, se puede originar un hecho médico-sanitario dañoso, que involucra la vida e integridad física y mental del usuario en salud. La acción constitucional de tutela se considera la herramienta más eficaz para la salvaguarda de los derechos humanos y fundamentales del paciente, y es la acción constitucional más recurrida por el usuario médico. Hay que aclarar que la tutela es una acción constitucional y no un recurso procesal, que no precisa de la intervención de un abogado.

Por un lado, existen dos acciones colectivas: la acción popular y la de grupo. A la primera pueden acudir los usuarios en salud, y es un mecanismo de amparo de los derechos colectivos del paciente, que se asocian con la salubridad pública y la prestación médico-sanitaria. A su vez, la acción constitucional de grupo, al ser invocada demanda que exista una pluralidad de pacientes víctimas de daños generadores de perjuicios; menoscabo al paciente, que debe ser originado por el mismo hecho doloso o culposo, a quien se le causa una lesión individual.

Por otro, los daños punitivos que podrían administrarse en el derecho médico-sanitario, se definen como juicios de reproche ejemplarizante, cuyo propósito es el de modificar el comportamiento del prestador sanitario. La aplicación de la citada teoría de los punitive damages, es improcedente en la actualidad en Colombia para la actividad médica, es decir, no es suministrada por los operadores judiciales para sancionar a los victimarios prestadores en salud; no obstante, si el fin es cambiar el comportamiento temerario, en ciertas actuaciones, del recurso humano en salud o del representante de la institución sanitaria, se hace imprescindible el empleo de esta teoría, que busca amparar los derechos del paciente potencial víctima del daño médico o sanitario.

Una vez realizada esta breve introducción, se continúa con el problema de investigación a responder mediante una hipótesis, de la siguiente manera:

¿Existen en Colombia mecanismos para la salvaguarda de los derechos humanos y fundamentales del paciente, potencial víctima del hecho médico-sanitario generador de daños? 
La hipótesis que se presenta en este texto y que da respuesta a la pregunta-problema, es que efectivamente existen en Colombia procedimientos para la protección de los derechos de los pacientes. La acción de tutela o amparo, las acciones colectivas de grupo y populares, así como la aplicación de la teoría de los daños punitivos, que son multas civiles a cargo del prestador en salud creador de perjuicios al paciente, son medios de protección de los derechos del paciente, y se estudian en esta investigación.

Este escrito en el que se exterioriza un problema de investigación y una hipótesis que se despliega en núcleos temáticos, es resultado de un estudio de naturaleza exploratoria de revisión, a través del cual se examina, reúne, revisa y a la vez integra, el producto de una investigación de tipo bibliográfico, en la que se agruparon y sistematizaron los documentos relacionados con el tema objeto de la análisis; tema que se vincula con la presentación de los principales instrumentos de salvaguarda de los derechos humanos y fundamentales del paciente en Colombia.

Con el fin de demostrar la hipótesis, este artículo se desarrolla en los siguientes ejes temáticos: en principio, (i) se hace alusión al usuario del servicio médico en su calidad de víctima, para en seguida, (ii) presentar la acción de tutela, (iii) analizar la acción popular así como también (iv) la acción colectiva de grupo indemnizatoria, y v) por último, referir los daños punitivos, instituidos todos, como dispositivos de protección de los derechos humanos y constitucionales del paciente. Para finalizar se dan algunas reflexiones, conclusiones o hallazgos de la investigación efectuada.

\section{EL USUARIO DEL SERVICIO MÉDICO POTENCIAL VÍCTIMA DEL HECHO MÉDICO-SANITARIO}

Es relevante destacar la actividad que ejecutan los profesionales de la salud, considerada como una de las más significativas; lo anterior porque en la prestación de servicios sanitarios, se involucra la vida e integridad física del paciente, quien demanda la protección de sus derechos de forma integral. Por ende, se hace un especial reconocimiento al recurso humano en salud, quien con sacrificio procura el bienestar físico y mental del paciente -usuario del servicio médico que confía en la solución de sus inconvenientes de salud-y realizó extensos estudios para lograr la pericia exigida en la prestación sanitaria y ejecutar de esta manera diagnósticos certeros en beneficio del usuario médico.

Por lo tanto, el estudiante de medicina, el profesor de las ciencias de la salud ${ }^{1}$ y la universidad o institución donde se forma el profesional médico de manera integral, deben tener una meta clara: salvaguardar los derechos de los pacientes; usuarios del servicio médico, que requieren de la atención de un profesional de la salud ${ }^{2}$, con el objetivo de "[...] reducir o eliminar el sufrimiento, la disminución o el control del dolor, así como la lucha contra la muerte, como expresión del instinto natural de proteger y querer conservar [...]" (Lombana, 2007, p. 25) la vida del ser humano. De no ser así, el paciente se convierte en

1 Se transcribe un interesante mensaje de un profesor de medicina a sus alumnos: "Ya cerca del fin del ciclo lectivo quiero compartir con ustedes, Sres. estudiantes, algo que para todos los médicos del mundo es la síntesis de lo que debemos hacer en nuestro comportamiento profesional: el Juramento Hipocrático. No basta con haber aprobado todos los exámenes que la carrera de medicina exige para ejercer la profesión. Al concluir esa etapa de vida estudiantil (que nunca más se repetirá) y en uno de los actos más solemnes que pueden ocurrir en la historia de una persona, hace falta jurar ante las autoridades de la facultad, ante sus compañeros, ante sus familias y ante el pueblo este conjunto de reglas. Hay numerosas leyes vigentes en todo el mundo que regulan el ejercicio de la medicina pero, en última instancia, en el momento de la relación médico-paciente, la única norma que rige nuestro comportamiento ético es este juramento que todos los médicos del mundo hemos hecho y que ustedes harán en pocos años. Los contenidos del mismo son tan claros que eximen de cualquier opinión o comentario adicional. Como última actividad extracurricular quiero, entonces, que conozcan las dos versiones del Juramento Hipocrático: la original y la que se aplica actualmente, desde hace décadas. Y espero que cuando llegue el momento en que deban jurar sientan la misma emoción que hemos tenido todos los que algún día decidimos dedicarnos a la medicina, que más que una profesión es una forma de vida" (San Juan, 2008, p 1).

2 Para estudiar lo atinente a las políticas del Gobierno colombiano en relación con los temas de la salud, se recomienda leer a Galindo (2011). 
potencial víctima de un hecho médico-sanitario generador de daño, que a su vez causa perjuicios.

\section{EL JURAMENTO HIPOCRÁTICO EN BENEFICIO DE LA VÍCTIMA}

El estudiante de medicina al terminar su formación universitaria, realiza el denominado "juramento hipocrático", que revela la importancia de la profesión médica. Los galenos al obtener su grado de médico, hacen el siguiente juramento:

Juro por Apolo médico, por Esculapio, Higía y Panacea y pongo por testigos a todos los dioses y a todas las diosas, cumplir según mis posibilidades y razón el siguiente Juramento: Estimaré como a mis padres a aquel que me enseñó este arte, haré vida común con él y si es necesario partiré con él mis bienes; consideraré a sus hijos como hermanos míos y les enseñaré este arte sin retribución ni promesa escrita, si necesitan aprenderlo. Comunicaré los principios, lecciones y todo lo demás de la enseñanza a mis hijos, a los del maestro que me ha instruido, a los discípulos regularmente inscriptos y jurados según los reglamentos, pero a nadie más.

Aplicaré los regímenes en bien de los enfermos según mi saber y entender y nunca para mal de nadie. No daré a nadie, por complacencia, un remedio mortal o un consejo que lo induzca a su pérdida. Tampoco daré a una mujer un pesario que pueda dañar la vida del feto. Conservaré puros mi vida y mi arte. No extraeré cálculo manifiesto, dejaré esta operación a quienes saben practicar la cirugía.

En cualquier casa en que penetre, lo haré para el bien de los enfermos, evitando todo daño voluntario y toda corrupción, absteniéndome del placer del amor con las mujeres y los hombres, los libres y los esclavos. Todo lo que viere u oyere en el ejercicio de la profesión y en el comercio de la vida común y que no deba divulgarse lo conservaré como secreto. Si cumplo íntegramente con este Juramento, que pueda gozar dichosamente de mi vida y mi arte y disfrutar de perenne gloria entre los hombres. Si lo quebranto, que me suceda lo contrario (Escardó, 1954, p. 61).

El "juramento" transcrito, tiene íntima conexión con el derecho constitucional, los derechos humanos y el derecho de daños. Se identifican en el texto, normas reglas y principios constitucionales como el respeto a la vida e integridad física del paciente, la garantía de su autonomía de la voluntad y el secreto profesional, que al ser quebrantados, se aplica toda la estructura jurídica del derecho de daños; lo precedente, con el propósito de proteger los derechos de las víctimas del daño galénico.

Por su parte, la Asamblea General de las Naciones Unidas ${ }^{3}$, realiza una definición de víctima

\footnotetext{
"Las Naciones Unidas son una organización internacional fundada en 1945 tras la Segunda Guerra Mundial por 51 países que se comprometieron a mantener la paz y la seguridad internacionales, fomentar entre las naciones relaciones de amistad y promover el progreso social, la mejora del nivel de vida y los derechos humanos.

Las Naciones Unidas tienen entre sus principales objetivos

- Mantener la paz y la seguridad internacionales;

- Fomentar relaciones de amistad entre las naciones;

- Ayudar a las naciones a trabajar unidas para mejorar la vida de los pobres, vencer el hambre, las enfermedades y el analfabetismo, y fomentar el respeto de los derechos y libertades de los demás;

- Servir de centro que armonice los esfuerzos de las naciones por alcanzar estos objetivos comunes.
}

Debido a su singular carácter internacional, y las competencias de su Carta fundacional, la Organización puede adoptar decisiones sobre una amplia gama de temas, y proporcionar un foro a sus 193 Estados Miembros para expresar sus opiniones, a través de la Asamblea General, el Consejo de Seguridad, el Consejo Económico y Social y otros órganos y comisiones.

La labor de las Naciones Unidas llega a todos los rincones del mundo. Aunque es más conocida por el mantenimiento de la paz, la consolidación de la paz, la prevención de conflictos y la asistencia humanitaria, hay muchas otras maneras en que las Naciones Unidas y su sistema (organismos especializados, fondos y programas), afectan a nuestras vidas y hacen del mundo un lugar mejor. La Organización trabaja en una amplia gama de temas fundamentales, desde el desarrollo sostenible, medioambiente y la protección de los refugiados, socorro en casos de desastre, la lucha contra el terrorismo, el desarme y la no proliferación, hasta la promoción de la democracia, los derechos humanos, la igualdad entre los géneros y el adelanto de la mujer, la gobernanza, el desarrollo económico y social y la salud internacional, la remoción de minas terrestres, la expansión de la producción de alimentos, entre otros, con el fin de alcanzar 
que puede emplearse para el paciente, quien es sujeto pasivo de un hecho médico-sanitario generador de daños.

\section{EL CONCEPTO DE VÍCTIMA DEL DAÑO MÉDICO-SANITARIO}

La Organización de las Naciones Unidas (ONU) señala que la víctima es la persona natural que de forma individual o colectiva ha sufrido un daño, en este caso, instituido como un elemento del derecho de daños acompañado del hecho $y$ el nexo de causalidad. El daño que genera perjuicios, continúa la ONU, es una lesión física o mental relacionada con el sufrimiento emocional (del paciente); de la misma manera, el daño también ocasiona el detrimento financiero de la víctima, que menoscaba los derechos humanos y fundamentales del usuario en salud.

El usuario del servicio médico, puede sufrir una lesión de carácter temporal o permanente, debido a la acción u omisión del prestador sanitario. El perjuicio al paciente, infringe las normas reglas y principios (ONU, 1985), contenidas en la Constitución Política de Colombia; normas legales y constitucionales, que requieren de un sistema procesal $^{4}$ para hacer efectivos los derechos del paciente víctima del daño. No obstante, la acción u omisión productora del daño, puede contrarrestarse por medio de instrumentos constitucionales: las acciones de tutela, populares y de grupo, forman parte de este tipo de herramientas.

\section{LA ACCIÓN DE TUTELA COMO MECANISMO DE PROTECCIÓN DE LOS DERECHOS DEL PACIENTE}

Por una parte, se establece que en la Constitución Política de Colombia no se consagra de modo

sus objetivos y coordinar los esfuerzos para un mundo más seguro para las generaciones presentes y futuras" (ONU, 1945, http://www.un.org/es/aboutun/).

4 Sistema consagrado en el denominado "Derecho Procesal Constitucional" que busca la efectiva protección de los derechos humanos y constitucionales de las personas (pacientes). Se recomienda el estudio de estos textos, para ampliar el concepto de derecho procesal constitucional: Alcalá (1947), Couture (1948), Fix-Zamudio (1964, 1984), García (1971), González, (1980) y Gozaíni (1988). concreto el derecho fundamental ${ }^{5}$ a la salud. Sin embargo, la Corte Constitucional colombiana determinó que ante una probable transgresión de la dignidad humana del paciente, del derecho a la vida, o por expresa aplicación del bloque de constitucionalidad de derechos humanos ratificados por Colombia, la salud es un derecho fundamental. Derecho que puede protegerse a través de la acción constitucional de tutela.

En Colombia, la acción constitucional de tutela ha repercutido de forma positiva en el bienestar de las personas, porque las facultades de los jueces constitucionales y de la Corte Constitucional, han permitido la protección de los derechos del paciente. La norma constitucional, dispone que toda persona, incluido el paciente,

[...] tendrá acción de tutela para reclamar ante los jueces, en todo momento y lugar,

En cuanto al concepto de derecho fundamental, se ha dicho lo siguiente: "En sentencia T-418 de 1992 señaló que "los derechos obtienen el calificativo de fundamentales en razón de su naturaleza, esto es, por su inherencia con respecto al núcleo jurídico, político, social, económico y cultural del hombre. Un derecho es fundamental por reunir estas características y no por aparecer reconocido en la Constitución Nacional como tal. Estos derechos fundamentales constituyen las garantías ciudadanas básicas sin las cuales la supervivencia del ser humano no sería posible'. [...] Por su parte, en sentencia T-419 de 1992 señaló que 'los derechos fundamentales son los que corresponden al ser humano en cuanto tal, es decir, como poseedor de una identidad inimitable caracterizada por su racionalidad que le permite ejercer sus deseos y apetencias libremente. De ahí que se le reconozca una dignidad-la dignidad humana- que lo colocan en situación de superior en el universo social en que se desenvuelve, y por ello, es acreedor de derechos que le permiten desarrollar su personalidad humana y sin los cuales esta se vería discriminada, enervada y aún suprimida. Son los derechos fundamentales que le protegen la vida, proscriben la tortura, aseguran su igualdad frente a sus congéneres, amparan su derecho a la intimidad, garantizan su libertad de conciencia, de cultos, de expresión y pensamiento; salvaguardan su honra, le permiten circular libremente, le preservan el derecho al trabajo, a la educación y a la libertad de escogencia de una profesión u oficio, las libertades de enseñanza, aprendizaje, investigación y cátedra; su juzgamiento debe respetar el debido proceso, se le garantiza el derecho a la libre asociación y a formar sindicatos, etc."' (Corte Constitucional de Colombia, 2003, p. 8). Para ampliar el tema del derecho fundamental a la salud, véase: López (2008). 
mediante un procedimiento preferente $y$ sumario, por sí misma o por quien actúe a su nombre, la protección inmediata de sus derechos constitucionales fundamentales, cuando quiera que estos resulten vulnerados o amenazados por la acción o la omisión de cualquier autoridad pública. La protección consistirá en una orden para que aquel respecto de quien se solicita la tutela, actúe o se abstenga de hacerlo. El fallo, que será de inmediato cumplimiento, podrá impugnarse ante el juez competente y, en todo caso, este lo remitirá a la Corte Constitucional para su eventual revisión. Esta acción solo procederá cuando el afectado no disponga de otro medio de defensa judicial, salvo que aquella se utilice como mecanismo transitorio para evitar un perjuicio irremediable. En ningún caso podrán transcurrir más de diez días entre la solicitud de tutela y su resolución. La ley establecerá los casos en los que la acción de tutela procede contra particulares encargados de la prestación de un servicio público o cuya conducta afecte grave y directamente el interés colectivo, o respecto de quienes el solicitante se halle en estado de subordinación o indefensión (Constitución Política de Colombia, 1991, art. 86).

Por otra parte, es otorgado a todos los jueces el llamado "control difuso". Por medio de este, los jueces de la República de diferente índole pueden tutelar los derechos del paciente, cuando consideren que una norma vulnera sus derechos constitucionales. No obstante, existe también un modelo "concentrado" a cargo de la Corte Constitucional de Colombia, quien es la que determina en definitiva, si la norma infringe los derechos del paciente; el control mixto de constitucionalidad aplicado, busca la salvaguarda de los derechos del usuario médico, y a su vez procura cumplir con los convenios internacionales ratificados por Colombia.

Inclusive, hay quienes expresan que la alta corporación que defiende los intereses y derechos de las personas, entre estas los pacientes, es "la Corte Constitucional más interesante en el con- texto latinoamericano. Pero su modelo, como ya ha sido señalado, puede considerarse mixto, aun cuando con evidentes peculiaridades" (García, 1971, p. 8).

\section{EL EVENTO ADVERSO QUE LESIONA LOS DERECHOS DEL PACIENTE}

El derecho a la salud de una persona, puede ser transgredido por el operador en salud, ya sea por acción o por omisión en la prestación del servicio. El paciente en la ejecución del contrato de prestación de servicios médicos, puede ser víctima (Corte Constitucional de Colombia, $2002)^{6}$ del denominado evento adverso. Evento que hace alusión

[...] a las lesiones o complicaciones involuntarias que ocurren durante la atención en salud, los cuales son más atribuibles a esta que a la enfermedad subyacente y que pueden conducir a la muerte, la incapacidad o al deterioro en el estado de salud del paciente, a la demora del alta, a la prolongación del tiempo de estancia hospitalizado y al incremento de los costos de no-calidad. Por extensión, también aplicamos este concepto a situaciones relacionadas con procesos no asistenciales que potencialmente pueden incidir en la ocurrencia de las situaciones arriba mencionadas (Ministerio de la Protección Social, 2006, p 78).

Como se indicó, los eventos adversos se presentan en la prestación en salud, y por este hecho se pueden violar los derechos del usuario del servicio médico a la vida e integridad física y psíquica. Sin embargo, no únicamente por la presencia de eventos adversos se pueden vulnerar los derechos del paciente, porque la negativa a la prestación del servicio médico de una persona no incluida

\footnotetext{
6 La alta corporación al hacer referencia a las víctimas y los perjudicados hace la siguiente reflexión: "A partir del año 2002, definió claramente lo que se debía entender por víctima [...] y [...] perjudicado [...] Según el alto tribunal, víctima (es la persona respecto de la cual se materializa la conducta [...]), perjudicado (tiene un alcance mayor en la medida en que comprende a todos los que han sufrido un daño así no sea patrimonial) [...]"(Corte Constitucional de Colombia, 2002, p 15)
} 


\section{Gráfica 1.}

\section{Modelo explicativo}

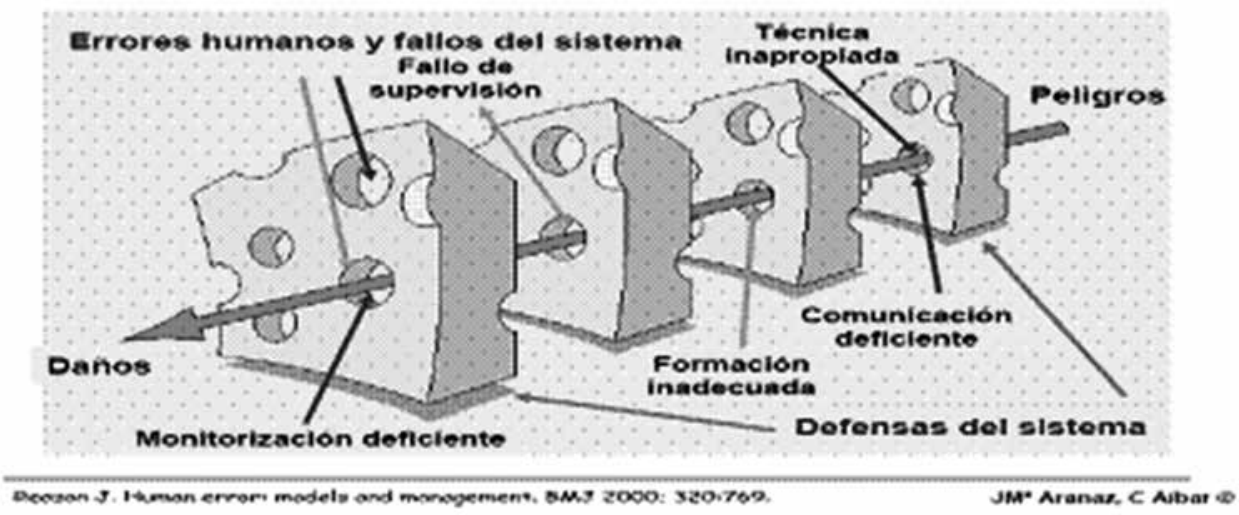

Fuente: Observatorio de Calidad de la Atención en Salud (s. f.).

en el plan obligatorio de salud, también representa la transgresión del derecho fundamental a la salud. En este sentido,

[...] la jurisprudencia reitera que se desconoce el derecho a la salud de una persona que requiere un servicio médico no incluido en el plan obligatorio de salud, cuando "(i) la falta del servicio médico vulnera o amenaza los derechos a la vida y a la integridad personal de quien lo requiere; (ii) el servicio no puede ser sustituido por otro que se encuentre incluido en el plan obligatorio; (iii) el interesado no puede directamente costearlo, ni las sumas que la entidad encargada de garantizar la prestación del servicio se encuentra autorizada legalmente a cobrar, y no puede acceder al servicio por otro plan distinto que lo beneficie; $y$ (iv) el servicio médico ha sido ordenado por un médico adscrito a la entidad encargada de garantizar la prestación del servicio a quien está solicitándolo" [...] (Corte Constitucional, 2010, p 12) ${ }^{7}$.

7 "Estos criterios fueron establecidos en estos términos por la sentencia T-1204 de 2000 [MP Alejandro Martínez Caballero] y reiterados así, entre otras, por las sentencias T-1022 de 2005 [MP Manuel José Cepeda Espinosa],
De exteriorizarse esta situación, el usuario del servicio médico puede presentar las acciones constitucionales pertinentes, preferentemente la acción de amparo o tutela como se designa en Colombia, por errores humanos, negativas de atención o fallas en el sistema de salud. En suma, el evento adverso lesiona los derechos del paciente, pero la vulneración del derecho a

T-557 y T-829 de 2006 [MP Manuel José Cepeda Espinosa], T-148 de 2007 [MP Humberto Antonio Sierra Porto], T-565 de 2007 [MP Clara Inés Vargas Hernández], T-788 de 2007 [MP Rodrigo Escobar Gil] y T-1079 de 2007 [MP Humberto Antonio Sierra Porto]. En la sentencia T-1204 de 2000 [MP Alejandro Martínez Caballero], en el contexto del régimen contributivo de salud; en este caso la Corte ordenó a la entidad encargada de garantizarle al peticionario la prestación del servicio de salud (Colmena Salud EPS) que autorizara la práctica del servicio requerido (examen de carga viral). La Corte tuvo en cuenta que según la jurisprudencia constitucional, el juez de tutela puede ordenar '[... ] la prestación de los servicios de salud, a los cuales las personas no tienen el derecho fundamental a acceder, cuando sin ellos se haría nugatoria la garantía a derechos constitucionales fundamentales como la vida y la integridad personal, pues frente a estos derechos, inherentes a la persona humana $e$ independientes de cualquier circunstancia ajena a su núcleo esencial, no puede oponerse la falta de reglamentación legal (decisión política) o la carencia de recursos para satisfacerlos"” (Sentencia T-363/2010). 
la salud, no necesariamente se presenta por el evento adverso.

\section{EL DERECHO FUNDAMENTAL A LA SALUD}

La Corte Constitucional colombiana ha definido a la salud, protegida a través de la acción de tutela, como un "[...] estado variable, susceptible de afectaciones múltiples, que inciden en mayor o menor medida en la vida del individuo" (Corte Constitucional de Colombia, 1993, 22) 8 y por consiguiente, no se trata de que la persona tenga buena salud o carezca de ella, porque la salud del paciente debe valorarse de manera integral en cada caso concreto. En síntesis, la salud no se afilia únicamente con la ausencia de enfermedad, sino con un estado completo e integral de bienestar físico, mental y social, todo, dentro del nivel óptimo posible de sanidad para una persona (Corte Constitucional, 1993).

\section{LA PROTECCIÓN DEL DERECHO A LA SALUD A TRAVÉS DE LA JUSTICIA CONSTITUCIONAL}

En los términos del bloque de constitucionalidad de derechos humanos ratificados por Colombia, en cada Estado social y democrático, el derecho a la salud se relaciona con el nivel más alto de salud de la persona. Dicho nivel, se debe alcanzar de forma progresiva y prioritaria, con la implementación de políticas públicas que agencien la protección universal $e$ integral del derecho a la salud de los ciudadanos. Sin embargo, la jurisprudencia nacional y foránea advierte que el concepto de salud no es unívoco y absoluto, porque en un

"Estado social y democrático de derecho que se reconoce a sí mismo como pluriétnico y

8 "En este caso se protegió el derecho a la salud de un menor que había sufrido un deterioro en una pierna, en razón a la mala práctica de un servicio de salud que requería (una inyección que se le aplicó), en un primer momento, y a la negativa posterior de la institución (un hospital) para atender las secuelas causadas a la salud del menor, en un segundo momento" (Corte Constitucional de Colombia, 2008, p. 22). multicultural, la noción constitucional de salud es sensible a las diferencias tanto sociales como ambientales que existan entre los diferentes grupos de personas que viven en Colombia" 9 (Corte Constitucional de Colombia, 2008, p 22). $\mathrm{El}$ alto nivel de salud al que se hace referencia,

9 En la sentencia T-379/2003 (MP Clara Inés Vargas Hernández), por ejemplo, la Corte decidió entre otras cosas que "el derecho de las comunidades indígenas a escoger en forma libre e independiente la institución que administrará los recursos del régimen subsidiado de salud, del cual son destinatarios, es asunto de su autonomía $y$ tiene por finalidad conservar su integridad y unidad sociocultural". La Corte tuvo en cuenta, de acuerdo con "el Convenio 169 de la OIT, sobre pueblos indígenas y tribales en países independientes, [...] que los regímenes de seguridad social deberán extenderse progresivamente a los pueblos interesados y aplicárseles sin discriminación alguna [el artículo 24], para lo cual preceptúa que los gobiernos deberán velar porque se pongan a disposición de los pueblos interesados servicios de salud adecuados o proporcionar a dichos pueblos los medios que les permitan organizar y prestar tales servicios 'bajo su propia responsabilidad y control', a fin de que puedan gozar del máximo nivel posible de salud física y mental (art. 25.1). [... . Agrega el Convenio que los servicios de salud deberán organizarse, en la medida de lo posible, a nivel comunitario, y que deberán planearse y administrarse en cooperación con los pueblos interesados teniendo en cuenta 'sus condiciones económicas, geográficas, sociales y culturales, así como sus métodos de prevención, prácticas curativas y medicamentos tradicionales' (art. 25.2.). Dispone igualmente que el sistema de asistencia sanitaria deberá dar la preferencia a la formación y al empleo de personal sanitario de la comunidad local y centrarse en los cuidados primarios de salud, manteniendo al mismo tiempo estrechos vínculos con los demás niveles de asistencia sanitaria (art. 25.3) y que la prestación de tales servicios de salud deberá coordinarse con las demás medidas sociales, económicas y culturales que se tomen en el país (art. 25.4.). En consonancia con este instrumento internacional, el Congreso expidió la ley 691 de 2001 por medio de la cual se reglamenta la participación de los grupos étnicos en el sistema general de seguridad social en salud. Dicho ordenamiento tiene por objeto 'proteger de manera efectiva los derechos a la salud de los pueblos indígenas, garantizando su integridad cultural de tal manera que se asegure su permanencia $e$ integridad' (art. $1^{\circ}$ ). Así mismo, allí se establece que para la interpretación y aplicación de dicha ley se debe tener en cuenta, particularmente, el principio de la diversidad étnica y cultural en virtud del cual 'el sistema practicará la observancia y el respeto a su estilo de vida y tomará en consideración sus especificidades culturales y ambientales que les permitan un desarrollo armónico a los pueblos indígenas' (art. $3^{\circ}$ )" (Corte Constitucional de Colombia, 2008, p. 22). 
se puede alcanzar a través de la justicia constitucional, por cuanto

[...] al incorporar los contenidos propios del derecho procesal, sus elementos constitutivos, sus instituciones y mecánicas, introduce aspectos funcionales a la definición estática de las nociones constitucionales, especialmente en relación con la ejecución de los derechos fundamentales y los modos de resolver las frecuentes violaciones. A su vez, el derecho procesal cobra una nueva perspectiva como estructura viabilizadora de la eficacia de las instituciones constitucionales, superando la caracterización más común como medio para resolver los conflictos intersubjetivos. El balance muestra una potenciación de ambas disciplinas que se concreta en otra distinta y particular, caracterizada por problemáticas específicas más relacionadas con la funcionalidad de las instituciones democráticas y su misión realizadora del Estado de Derecho. La proyección es superadora tanto para el derecho procesal como para el constitucional y permite especular sobre la evolución desde los aspectos formales del derecho hacia la elaboración de nuevos y originales mecanismos jurídicos para la efectiva protección y promoción de los derechos humanos (Loriano, 2009, p. 183).

Así las cosas, es viable la protección de los derechos cardinales del paciente consagrados en la Carta Política de los colombianos, con la aplicación del derecho procesal constitucional. Adicionalmente, es relevante indicar que los sistemas normativos colombianos, están integrados por ordenamientos jurídicos de rango constitucional y legal, que se vinculan con la protección del derecho a la salud del paciente, con la implementación de normas reglas y normas principios ${ }^{10}$, que salvaguardan los derechos

10 Para ilustrar acerca de la diferencia entre normas y reglas principios se presenta el siguiente ejemplo: "Se transcriben a continuación dos normas: [norma I:] toda persona tiene derecho a que se respete su integridad física, psíquica y moral. 7 [Norma II:] durante el proceso, toda persona tiene derecho, en plena igualdad, a las siguientes garantías mínimas: a) derecho del inculpado de ser asistido gratui- fundamentales del paciente a la salud, integridad física y la reparación integral, en este último caso, cuando se exterioriza el hecho médico-sanitario generador de daños al usuario médico.

En suma, el derecho procesal constitucional, el derecho constitucional y la acción de tutela, hasta ahora estudiados, propenden por la protección de los derechos del paciente. Prueba de la anterior afirmación, es el número de acciones de amparo presentadas por ciudadanos colombianos, buscando la protección, entre otros, del derecho a la salud; acciones que se incrementan de forma periódica, tal como se indica en la tabla 1.

tamente por el traductor o intérprete, si no comprende o no habla el idioma del juzgado o tribunal. 8 Ambas normas forman parte de la Convención Americana de Derechos Humanos. La norma I es un principio, la II, una regla. Las diferencias estructurales entre una y otra se advierten, según la mayoría de los autores, básicamente desde dos niveles de análisis distintos. Cabe examinarlos a continuación, para pasar luego al análisis de una muy interesante crítica que han recibido recientemente: a) en primer lugar, las normas transcritas son distintas en cuanto a su fuerza deóntica. En efecto, por su propia índole, la prescripción de la norma I (el respeto de la integridad física, psíquica y moral) puede ser llevada a cabo en más o en menos, es decir, admite distintos niveles de cumplimiento (o de incumplimiento). Lo que la norma ordena es que sea observada en la mayor medida posible, en otras palabras, que sea optimizada. La norma II, en cambio, ordena un algo que no admite distintos niveles de cumplimiento. Puede ser observada o no: no hay puntos intermedios, o el inculpado tiene la asistencia de un intérprete o no la tiene. Esta diferencia es causa de que la interpretación de los principios sea con frecuencia más complicada que la de las reglas. Sobre la base de lo dicho, R. Alexy ha caracterizado los principios como 'mandatos de optimización'. 9 b) Cuando mejor se percibe la diferencia entre reglas y principios es en el momento de su aplicación. Más concretamente, en el momento de su colisión o conflicto con otras normas.10 En los casos de conflictos entre reglas hay que decidir la precedencia de una u otra, y esa decisión conllevará la anulación de la regla preterida. Un conflicto de reglas, en efecto, 'solo puede ser solucionado o bien introduciendo en una de las reglas una cláusula de excepción que elimina el conflicto o declarando inválida, por lo menos, una de las reglas'. 11 Imaginemos que a la norma II se le opone esta otra regla: norma III: durante el proceso, los inculpados de nacionalidad argentina no tienen derecho a ser asistidos gratuitamente por un traductor o intérprete, puesto que se presupone su conocimiento del idioma nacional" (Alexy, 2000, pp. 294-304). Cfr. (Cianciardo, 2011). Cfr. (Seaone, 2005). 
Tabla 1.

\begin{tabular}{|l|l|l|}
\hline \multicolumn{3}{|c|}{$\begin{array}{c}\text { REGISTRO DE TUTELAS EN COLOMBIA } \\
\text { PERIODO 1999 - 2005 }\end{array}$} \\
\hline \multicolumn{1}{|c|}{ AÑO } & \multicolumn{1}{|c|}{$\mathbf{N}^{\circ}$ tutelas } & \multicolumn{1}{c|}{ Crecimiento anual } \\
\hline 1999 & 86.313 & - \\
\hline 2000 & 131.764 & $52,66 \%$ \\
\hline 2001 & 133.272 & $1,14 \%$ \\
\hline 2002 & 143.887 & $7,96 \%$ \\
\hline 2003 & 149.439 & $3,86 \%$ \\
\hline 2004 & 198.125 & $32,58 \%$ \\
\hline 2005 & 224.270 & $13,20 \%$ \\
\hline Total & $11^{\prime} 067.070$ & \\
\hline
\end{tabular}

Fuente: Defensoría del pueblo (2007, p. 25).

\section{LA ACCIÓN POPULAR Y LA PROTECCIÓN DEL PACIENTE}

La víctima directa o el perjudicado por rebote $e^{11}$ del daño médico-sanitario producido por el prestador en salud, cuenta con la facultad de demandar que sus derechos sean protegidos, a través de las acciones constitucionales consagradas en la Carta Política colombiana. Una muestra de ello, son las acciones constitucionales destinadas a salvaguardar los derechos colectivos de las personas; acciones como las populares, son medios procesales que aseguran la protección de rango judicial, de los derechos e intereses de los pacientes, que pueden resultar afectados o en su defecto amenazados por las empresas promotoras o prestadoras de los servicios en salud públicas o privadas ${ }^{12}$.

\section{OBJETIVOS DE LAS ACCIONES POPULARES}

Las acciones populares tienen los siguientes propósitos: "a) evitar el daño contingente (pre-

11 Los perjudicados por rebote, también son denominados indirectos causahabientes (familiares) y no causahabientes.

12 "La salud pública está constituida por un conjunto de políticas que busca garantizar de manera integrada, la salud de la población por medio de acciones dirigidas tanto de manera individual como colectiva ya que sus resultados se constituyen en indicadores de las condiciones de vida, bienestar y desarrollo. Dichas acciones se realizarán bajo la rectoría del Estado y deberán promover la participación responsable de todos los sectores de la comunidad" (Congreso de la República de Colombia, 2007, art. 32). ventiva); b) hacer cesar el peligro, la amenaza, la vulneración o el agravio sobre esa categoría de derechos e intereses (suspensiva); c) o restituir las cosas a su estado anterior (restaurativa)" (Corte Constitucional de Colombia, 2011, p. 55). En este orden de ideas, el objetivo de las acciones populares es el de salvaguardar los derechos e intereses colectivos, en este caso de los pacientes, de todas las actividades que puedan ocasionar daños generadores de perjuicios, al usuario del sector salud, por la inadecuada prestación médica ${ }^{13}$ (Corte Constitucional de Colombia, 2011). En síntesis,

La Corte ha precisado que los derechos colectivos se caracterizan por ser derechos de solidaridad, participativos y no excluyentes, de alto espectro en cuanto no constituyen un sistema cerrado a la evolución social y política, que pertenecen a todos y cada uno de los individuos y que, como tales, exigen una labor anticipada de protección y una acción pronta de la justicia, inicialmente dirigida a impedir su afectación y, en su defecto, a lograr su inmediato restablecimiento, lo cual, precisamente, se logra a través de las

13 Así mismo, las acciones populares se pueden prestar por "una inadecuada explotación de los recursos naturales, los productos médicos defectuosos, la imprevisión en la construcción de una obra, el cobro excesivo de bienes o servicios, la alteración en la calidad de los alimentos, la publicidad engañosa, los fraudes del sector financiero, etc." (Corte Constitucional de Colombia, 2011, p. 6). 
llamadas acciones colectivas, populares y de grupo (Corte Constitucional de Colombia, 2011, p. 6).

La acción popular puede proteger el derecho a la salud de los colombianos, catalogado fundamental de acuerdo con lo que estableció el bloque de constitucionalidad de los tratados internacionales de derechos humanos ratificados por la República de Colombia (Corte Constitucional de Colombia, 2002). La citada acción, tiene una función preventiva de los daños que se pueden causar a los ciudadanos; habitantes del país que son usuarios del servicio médico, quienes demandan la protección del derecho a la salud cuando la situación así lo amerite, porque de lo contrario se ven amenazados los derechos a la vida e integridad física del usuario del servicio en salud, y por consiguiente su dignidad humana (Corte Constitucional de Colombia, 2002).

La tutela de los derechos del paciente, requiere $\mathrm{de}$ acciones colectivas, es decir, de acciones populares y de grupo, las cuales a través del derecho procesal constitucional, hacen eficaz la protección de los derechos humanos y a la vez fundamentales, relacionados con el amparo de la integridad física y mental del paciente. $\mathrm{El}$ nombrado derecho procesal, como ya se indicó, es una rama del derecho público que señala cuáles son las normas procesales de carácter orgánico y funcional, necesarias para el cumplimiento de las normas principios contenidas en la Constitución Política de los colombianos (Colombo, 2002).

\section{Legitimados por activa}

Las acciones populares pueden ser promovidas por los pacientes, potenciales víctimas de eventos adversos generados en la prestación médica, así como también por parte de personas jurídicas que consideren puedan verse lesionados sus derechos. Por ejemplo, derechos de los entes jurídicos que pueden ser transgredidos por empresas farmacéuticas que pretenden monopolizar un medicamento, en detrimento de los intereses propios y de los futuros usuarios de productos con destino a curar o neutralizar los efectos de una enfermedad.

Existen ejemplos que son reprochables de ser ciertos, en los que algunas compañías farmacéuticas crean medicamentos únicamente para los pacientes occidentales, porque son los que en efecto tienen la posibilidad de sufragar el costo de los mismos ${ }^{14}$. Las acciones colectivas populares a las que puede recurrir una pluralidad de víctimas del daño médico, tienen unas características que se expondrán a continuación.

14 En los medios de comunicación, hay columnas de opinión que presentan situaciones donde se vulneran los derechos de los pacientes. En este sentido, se ha aseverado que es reprobable privilegiar "la ganancia sobre la vida de los pacientes pobres, sino que evidencian que las patentes en medicamentos tienen al menos dos efectos muy problemáticos en términos del derecho a la salud [...] Primero, distorsionan las prioridades en la investigación. Como el propósito es obtener un monopolio rentable, entonces la investigación se dirige exclusivamente a crear medicamentos que tengan una demanda estable de pacientes con capacidad de pago. Eso ha permitido a veces avances en medicamentos para ciertas enfermedades crónicas, propias de sociedades de alto ingreso, pues ahí la patente brinda ganancias altas: pacientes que pueden pagar medicamentos costosos por largos años. Pero por esa misma razón, las patentes desincentivan la investigación sobre productos que permitan curar inmediatamente enfermedades de personas pobres o prevenirlas. No es entonces sorprendente que no sea prioridad de las farmacéuticas investigar sobre la vacuna de la malaria, que sigue matando a miles de personas. Segundo, las patentes implican, en ciertos casos, obstáculos infranqueables para que los países y poblaciones pobres puedan acceder a medicamentos que salvan vidas, como Nexavar, pues otorgan a las farmacéuticas la posibilidad de imponer precios muy altos, ya que gozan de un monopolio legal por décadas. No parece posible eliminar hoy las patentes sobre medicamentos, pero estas dos distorsiones obligan a defender al menos dos cosas: i) una investigación pública vigorosa, para que haya avances en los campos no rentables para las farmacéuticas, y ii) que nuestros Estados usen con fuerza el régimen de flexibilidades permitidos por los Adpic, como las licencias obligatorias, las importaciones paralelas o el control de precios, para evitar que las patentes se vuelvan obstáculos al acceso a medicamentos. Nuestros Estados tienen el deber moral y jurídico de asegurar que el régimen de patentes respete el derecho a la salud; esto es, que sea 'saludable', según la expresión del profesor español Xavier Seuba” (Uprimny, 2014). 


\section{CARACTERÍSTICAS DE LAS ACCIONES POPULARES}

Las acciones populares en defensa de los derechos colectivos de las personas, cuentan con unas características especiales, que son relacionadas por la Corte Constitucional de Colombia, de la siguiente manera:

a) Las acciones populares pueden ser promovidas por cualquier persona, natural o jurídica, a nombre de la comunidad cuando ocurra un daño o amenaza a un derecho o interés común, sin más requisitos que los que establezca el procedimiento regulado por la ley; b) las acciones populares son ejercidas contra las autoridades públicas por sus acciones y omisiones y por las mismas causas, contra los particulares, en razón a su posición dominante frente a la mayoría de la comunidad; c) las acciones populares tienen un fin público, la protección de un derecho colectivo; d) las acciones populares son de naturaleza preventiva, luego su ejercicio o promoción judicial no está supeditado o condicionado a que exista un daño o perjuicio de los derechos o intereses que se buscan proteger, basta con que se presente la amenaza o el riesgo de que se produzca el daño; $e$ ) las acciones populares tienen también un carácter restitutorio, en la medida en que persiguen el restablecimiento del uso y goce de los derechos e intereses colectivos; f) las acciones populares no persiguen en forma directa un resarcimiento de tipo pecuniario, aunque en algunos casos, el legislador ha previsto el reconocimiento de los gastos en que incurra el actor popular, o de una recompensa ${ }^{15}$, que, en todo caso, no puede convertirse en el único incentivo que ha de tener en cuenta quien debe obrar más por motivaciones de carácter altruista y solidario, en beneficio de la comunidad de la que forma parte; [y] g) las acciones populares gozan de una estructura especial que las diferencia de los demás procesos litigiosos, pues no plantean en estricto sentido una controversia entre partes

15 La "recompensa" fue eliminada de la normatividad que regula la acción popular. que defienden intereses subjetivos, sino que son un mecanismo de protección principal de los derechos colectivos preexistentes (Corte Constitucional de Colombia, 2011, p. 6).

Ciertamente, las acciones colectivas populares y de grupo indemnizatorias, propenden por la protección de los derechos de las víctimas efectivas o potenciales. Las últimas, a las que se hará referencia a continuación, han sido instituidas con el objetivo de conseguir la reparación integral del daño generador de perjuicios, producido a un número plural de personas, en este caso a usuarios del servicio médico y sanitario. El posible o exteriorizado daño, debe ser colectivo y no individual; para el último caso, se establece la acción constitucional de tutela o amparo, a la que ya se hizo referencia.

\section{LA ACCIÓN COLECTIVA DE GRUPO Y LA PROTECCIÓN DEL USUARIO DEL SERVICIO MÉDICO-SANITARIO}

Por una parte, la acción popular tiene el propósito de prevenir que el derecho colectivo de los pacientes, se vulnere. La acción colectiva popular demanda la existencia de un posible daño generador de perjuicios, que lesiona los derechos del usuario médico, que deben ser protegidos entre otras, por la Corte Constitucional de Colombia $^{16}$. Por otra, la acción de grupo cumple una

16 Las funciones de la Corte Constitucional de Colombia son las siguientes: "1. Decidir sobre las demandas de inconstitucionalidad que promuevan los ciudadanos contra los actos reformatorios de la Constitución, cualquiera que sea su origen, solo por vicios de procedimiento en su formación. 2. Decidir, con anterioridad al pronunciamiento popular, sobre la constitucionalidad de la convocatoria a un referendo o a una Asamblea Constituyente para reformar la Constitución, solo por vicios de procedimiento en su formación. 3. Decidir sobre la constitucionalidad de los referendos sobre leyes y de las consultas populares y plebiscitos del orden nacional. Estos últimos solo por vicios de procedimiento en su convocatoria y realización. 4. Decidir sobre las demandas de inconstitucionalidad que presenten los ciudadanos contra las leyes, tanto por su contenido material como por vicios de procedimiento en su formación. 5. Decidir sobre las demandas de inconstitucionalidad que presenten los ciudadanos contra los decretos con fuerza de ley dictados por el Gobierno con 
función de índole indemnizatoria o reparadora. Esta acción, está instituida como un mecanismo para la salvaguarda de los derechos colectivos de los pacientes, a la reparación integral de los perjuicios generados por el daño, en el marco de la justicia restaurativa ${ }^{17}$.

fundamento en los artículos 150 numeral[es] 10 y 341 de la Constitución, por su contenido material o por vicios de procedimiento en su formación. 6. Decidir sobre las excusas de que trata el artículo 137 de la Constitución. 7. Decidir definitivamente sobre la constitucionalidad de los decretos legislativos que dicte el Gobierno con fundamento en los artículos 212, 213 y 215 de la Constitución. 8. Decidir definitivamente sobre la constitucionalidad de los proyectos de ley que hayan sido objetados por el Gobierno como inconstitucionales, y de los proyectos de leyes estatutarias, tanto por su contenido material como por vicios de procedimiento en su formación. 9. Revisar, en la forma que determine la ley, las decisiones judiciales relacionadas con la acción de tutela de los derechos constitucionales. 10. Decidir definitivamente sobre la exequibilidad de los tratados internacionales y de las leyes que los aprueben. Con tal fin, el Gobierno los remitirá a la Corte, dentro de los seis días siguientes a la sanción de la ley. Cualquier ciudadano podrá intervenir para defender o impugnar su constitucionalidad. Si la Corte los declara constitucionales, el Gobierno podrá efectuar el canje de notas; en caso contrario no serán ratificados. Cuando una o varias normas de un tratado multilateral sean declaradas inexequibles por la Corte Constitucional, el presidente de la República solo podrá manifestar el consentimiento formulando la correspondiente reserva. 11. Darse su propio reglamento. Cuando la Corte encuentre vicios de procedimiento subsanables en la formación del acto sujeto a su control, ordenará devolverlo a la autoridad que lo profirió para que, de ser posible, enmiende el defecto observado. Subsanado el vicio, procederá a decidir sobre la exequibilidad del acto" (Olano, 2006, art. 241).

17 "Con la transformación del sistema penal contemplada en la reforma constitucional del año 2002, el incidente de reparación integral a la que el propio legislador le adscribió la condición de ser parte de los instrumentos de justicia restaurativa, como forma procesal mediante la cual se hace posible una solución efectiva y oportuna de reparación, adquirió un valor inmenso, en particular para la víctima, dejando de ser un procedimiento sobre cuestiones accesorias o secundarias y al contrario, constituyendo la oportunidad final, única, brevísima, dentro del proceso penal, para reclamar ni más ni menos que la reparación integral de la víctima por el daño causado por el hecho típico, antijurídico y culpable de un declarado penalmente responsable. Se convierte así el incidente en la instancia procesal para hacer efectiva la indemnización por parte de quien o quienes pueden ser considerados civilmente responsables o deban sufragar los costos de tales condenas (el declarado penalmente responsable, el tercero civilmente responsable y la aseguradora)" (Corte Constitucional de Colombia, 2009, p. 1).
El propósito de emprender la acción constitucional y colectiva de grupo, es que al paciente se le garantice el derecho fundamental a la reparación integral, por los perjuicios patrimoniales y extrapatrimoniales establecidos por la acción u omisión en la prestación negligente del servicio en salud; reparación integral, que junto con los derechos a la verdad y a la justicia, configuran los derechos fundamentales de mayor relevancia, en cuanto a la protección del amparo de las garantías constitucionales del paciente.

\section{DIFERENCIAS MÁS SIGNIFICATIVAS ENTRE LAS ACCIONES POPULARES Y DE GRUPO}

En principio, hay que señalar que para presentar la acción popular, no se requiere que exista un daño inminente y exteriorizado, es decir, no se precisa que a los usuarios del servicio médico se les haya causado un daño, o en su defecto que el medicamento defectuoso produzca el evento adverso, generador del quebranto de las facultades jurídicas del paciente.

El objetivo de las acciones populares, es de naturaleza preventiva, anticipada o pronosticada; en cambio las acciones de grupo o de clase, son instrumentos procesales de carácter colectivo $e$ individual, que demandan la reparación del daño producido al paciente o usuarios del servicio de salud determinados ${ }^{18}$. En este orden de ideas, las acciones colectivas son instrumentos de protección de los derechos de un número

18 Es el caso del daño generado por prótesis mamarias defectuosas, donde la pluralidad de víctimas es el común denominador. Más de doce mil mujeres pueden resultar siendo damnificadas de implantes mamarios generadores de daños al paciente. A este respecto: "En los procedimientos de implantes mamarios de prótesis en cirugías plásticas estéticas o con fines reconstructivos, se pueden generar daños a los pacientes; daños generadores de perjuicios, que pueden presentarse como consecuencia del implante de prótesis defectuosas a los usuarios de los servicios de salud, que deben ser indemnizados por los prestadores de estos servicios o del ente estatal encargado de la inspección, vigilancia y control. Para proteger su patrimonio, los victimarios legitimados por pasiva y potenciales generadores de daños, pueden trasladar los riesgos inherentes de su actividad a una compañía aseguradora” (López, 2013, p. 131). 
plural de víctimas; usuarios del servicio médico, que buscan la protección de sus derechos, en el caso de las acciones populares, o la reparación integral del perjuicio demandado, a través de la acción constitucional de grupo o también llamada acción de clase.

\section{¿POR QUÉ RAZÓN PRESENTAR UNA ACCIÓN DE GRUPO Y NO UNA DEMANDA DECLARATIVA DE RESPONSABILIDAD CIVIL O ADMINISTRATIVA?}

En la prestación de los servicios de salud, se pueden ocasionar daños a los pacientes, producidos por la negligencia por acción u omisión del prestador sanitario; daños que originan perjuicios materiales $e$ inmateriales al paciente, que deben indemnizarse mediante un proceso declarativo de responsabilidad civil, o por medio de una demanda de reparación directa, cuando el Estado es el causante del daño antijurídico. No se requiere para iniciar los citados procesos de un número plural de víctimas del daño galénico, por ende, puede presentarse por un único paciente perjudicado.

El fin de las anteriores acciones judiciales es el reconocimiento por parte del juez, de los derechos fundamentales del paciente; derechos a la verdad acerca de los hechos causantes del daño, a la justicia y a la indemnización integral de los perjuicios que se le provocaron. La vulneración a los derechos individuales y colectivos del usuario del servicio médico, debe repararse; para ello, existen acciones judiciales de naturaleza individual o acciones constitucionales colectivas, que tienen los mecanismos necesarios para lograr un propósito: garantizar los derechos de las víctimas del daño.

La acción colectiva de clase, requiere de condiciones uniformes de las personas que integran el grupo, en este caso, de pacientes víctimas directas e indirectas del daño médico-sanitario; condiciones uniformes que deben ser preexistentes a la ocurrencia del evento adverso causante de perjuicios. Así las cosas, tanto las acciones indemnizatorias declarativas de naturaleza civil o estatal, como las acciones constitucionales de grupo con carácter reparador, salvaguardan los intereses análogos del paciente víctima del daño. Por esto, y por el compromiso del legislador de proteger el interés social de la comunidad, es que se

[...] consideró necesario estatuir, para su protección, una acción especial y un proceso diferente para tramitar estas últimas. Esa es la razón por la cual "la garantía constitucional [de las acciones de grupo] se reduce a la alternativa de acudir a un mecanismo más ágil de defensa en un lapso prudencial, sin que con ello se elimine la posibilidad para los miembros de ese grupo, de ejercer, dentro de los términos ordinarios de caducidad, las acciones individuales que correspondan" (Corte Constitucional de Colombia, 2004, p. 11).

En suma, las acciones de tutela, populares y de grupo, se constituyen en mecanismos de protección de los derechos fundamentales del paciente; usuario a quien se le vulneran sus derechos de manera individual, o cuando existe pluralidad y homogeneidad de víctimas y daño, causante de perjuicios materiales e inmateriales al paciente. El daño, se reitera, es prevenible a través de la acción popular, o se busca su reparación por medio de la acción de grupo colectiva o de clase. A su vez, también existe la teoría del daño punitivo, al que se hará alusión enseguida, que es una herramienta eficaz para la protección de los derechos del usuario en salud.

\section{LOS DAÑOS PUNITIVOS: MULTAS CIVILES EJEMPLARIZANTES QUE PROTEGEN LOS DERECHOS DEL PACIENTE}

A continuación, se hará alusión a la aplicación de la teoría de los daños punitivos en Colombia, que se podrían suministrar con el objetivo de generar juicios de reproche ejemplarizantes al prestador en salud, cuyo propósito sería cambiar el comportamiento del deudor de la obligación, es decir, del prestador sanitario potencial victimario y legitimado por pasiva en un proceso judicial. En el ámbito de la responsabilidad médica y 
sanitaria, el derecho debe cumplir un objetivo fundamental: la generación de incentivos y sanciones dirigidas a la prevención de eventos adversos, que lesionan los derechos fundamentales y colectivos de los pacientes ${ }^{19}$. En el caso de las sanciones, resulta eficaz el uso de la teoría de los daños punitivos, porque estos son juicios de reproche con carácter ejemplarizante destinados al prestador en salud, quien con su actuar doloso o gravemente culposo, produce un menoscabo al paciente.

\section{DEFINICIÓN DE DAÑO PUNITIVO}

Los daños punitivos o punitive damages como son denominados en Estados Unidos y el Reino Unido, son un "plus" de indemnización concedido a favor de la víctima del hecho dañoso generador de perjuicios; esto es, los daños punitivos son sumas de dinero adicionales impuestas por el operador judicial al victimario, que rebasan la indemnización por perjuicios materiales $e$ inmateriales, liquidados en el proceso declarativo pertinente. La suma impuesta por el juez al victimario, en calidad de juicio de reconvención ejemplarizante, excede de la citada indemnización de los perjuicios patrimoniales y extrapatrimoniales; el nombrado monto, es proporcional al daño galénico, en este caso, causado al paciente, según el alcance y la naturaleza de los perjuicios que se produjeron (Reglero, 2009, citado en López, 2009) por el evento adverso ${ }^{20}$.

19 "Desde el punto de vista de las ciencias económicas, un ilícito civil se considera como un intercambio forzoso $e$ involuntario de derechos. Se entiende que en estos casos el mercado no funciona debido a los elevados costos de transacción si se pretendiera que el intercambio fuese voluntario. En efecto, es imposible, o prácticamente imposible, que dos conductores acuerden de manera previa cómo distribuirán los daños en caso de un accidente entre ellos. Se dice que en estos casos no pueden existir (como sí ocurre en el ámbito del derecho contractual) negociaciones eficientes, dado que los conductores no se conocen con anticipación" (Infante, 2013).

20 Hay que indicar, que el prestador en salud es un proveedor de un servicio de salud, que igualmente involucra productos (medicamentos, material con destino a la curación y procesos paliativos, entre otros). Dicho prestador, desarrolla de manera permanente u ocasional su actividad de forma profesional, dirigida al usuario de sus servicios, denominado "consumidor" (Senado de la Nación Argentina, 2008).

\section{LA APLICACIÓN DE LOS DAÑOS PUNITIVOS EN COLOMBIA}

En la actualidad en Colombia, no se aplican los daños punitivos, es decir, que la liquidación de perjuicios a cargo del victimario prestador en salud, únicamente comprende los perjuicios materiales e inmateriales; este hecho, puede suscitar la ausencia de un verdadero juicio de reproche ejemplarizante, esto es, que el prestador en salud no modifique su comportamiento, porque el monto de la indemnización a su cargo es insignificante. Lo anterior, es contrario al argumento que se presenta en esta investigación, porque se afirma que el derecho de daños y la aplicación de la teoría de los daños punitivos, el derecho constitucional $y$ procesal constitucional ${ }^{21}$, son mecanismos que salvaguardan los derechos fundamentales y colectivos de los pacientes. Existen países en América $^{22}$ (García, 1971) donde la teoría del daño

21 Señala el autor en esta misma página, lo siguiente en cuanto al derecho procesal: "Este último de carácter instrumental, es decir, de medio para obtener un fin. Y esto en forma relativamente reciente. Si bien es cierto que proceso hay desde siempre y en especial desde Grecia, Roma, [Bolonia], los glosadores y más tarde los codificadores del período revolucionario francés, lo concreto es que su autonomía y grado científico es tardío. Se acostumbra señalar su definitivo asentamiento en el siglo pasado, en especial desde 1868, con la aparición de la famosa obra de von Bülow que, entre otros aspectos, propugnó con éxito la autonomía de la acción y su desmembramiento del clásico concepto de derecho (entre otros aspectos más). Antes, lo procesal se confundía con lo sustantivo, y la difusión de las nuevas tesis solo tendrán acogida muy entrado el siglo XX, como lo demuestra, entre otros casos, que legislaciones procesales como la peruana, solo hayan sido modernizadas a raíz del nuevo Código Procesal Civil, que es de 1992. En igual sentido puede decirse de las llamadas clásicamente 'garantías constitucionales', originadas en el vocabulario jurídico de la famosa Declaración de los Derechos del Hombre de 1789, y de aquí pasó a toda la América Latina, donde se entendía como garantía, el derecho mismo, lo que ha causado confusiones durante décadas. Solo modernamente han empezado a separarse, a nivel de derecho positivo, los derechos, de las garantías (véase por ejemplo la Constitución de 1979, arts. 295-298 y la Constitución de 1993, art. 200). Pero esto es válido, en términos generales, en nuestro ámbito jurídico. En los Estados Unidos, como señalé anteriormente, el problema de la revisión judicial (judicial review) que es típicamente procesal, se trata en los manuales de derecho constitucional, sin que tal inclusión haya sido discutida (Barron \& Dienes, Constitutional Law, 1991).

22 Países como Estados Unidos y Argentina. En este último, a través de la ley del consumidor argentina (Buitrago, 2007). 
punitivo se está empleando, con el propósito de proteger el derecho constitucional a la salud $e$ integridad física del paciente; teoría, que no se ha incorporado en las normas reglas ni principios de la legislación colombiana y por tal razón, se realiza la propuesta de su aplicación con el fin de garantizar los derechos del usuario en salud.

\section{EL DAÑO PUNITIVO Y EL JUICIO DE REPROCHE}

Al imponer una sanción pecuniaria adicional al prestador en salud causante del daño, se busca que este modifique su comportamiento, es decir, que el hecho de imponerse una sanción económica agregada a la taxonomía de perjuicios establecidos en Colombia, haría que la conducta del prestador sanitario cambie. Se trata entonces de un reproche de tipo social y económico, un "plus" añadido a la indemnización a favor de la víctima directa o indirecta del hecho médico, causante del menoscabo de las facultades del paciente.

Esta situación traería beneficios al paciente, porque el recurso humano y administrativo en salud, alteraría de manera favorable su gestión en salud. El reproche social y económico dirigido al causante del daño de quien se demanda las reparaciones respectivas, con sumas adicionales cuando se actúa con culpa grave, dolo o dolo eventual $^{23}$, crea un beneficio considerable para el paciente.

23 El prestador médico en su actuar puede razonar y determinar si es probable o posible que cause daños al paciente. De ahí que "la posibilidad es la aptitud para hacer algo y la probabilidad se predica cuando hay buenas razones para creer que algo se verificará. [...] que el sujeto conozca que exista la posibilidad de que el resultado tenga lugar no marca ninguna diferencia entre dolo eventual y culpa consciente, pues en ambas categorías el conocimiento de esa aptitud es similar. No ocurre lo mismo con la probabilidad, ya que cuando ella se puede predicar está más cercana la materialización del evento: esas buenas razones para creer que se verificará, a las que he aludido precedentemente, hablan del conocimiento acerca de que el riesgo se traducirá -casi con seguridad- en resultado" (Terragani, 2009, p. 103). "La previsión de un evento como consecuencia meramente posible de la acción no implica necesariamente la voluntariedad del evento mismo, pero ello no excluye que la actitud de la voluntad frente al resultado previsto, de indiferencias o de ratificación del mismo, sean equivalentes a la voluntad del resultado" (Villalobos, 2002).
Se reitera que el hecho de incorporar la teoría de los daños punitivos en fallos judiciales que diriman los conflictos entre el prestador en salud y el paciente, produciría resultados positivos para la protección de los derechos humanos del usuario médico. La función disuasoria y preventiva de la mencionada teoría, salvaguarda los derechos a la vida e integridad física y mental del paciente, porque el comportamiento del prestador en salud, en virtud de la sanción, se transforma por cuanto la sanción impuesta por el juez, sería superior a la tasación e imposición de los perjuicios habituales.

En resumen, la sanción modifica la acción del prestador en salud, es decir, se actuaría con mayor diligencia, prudencia y observancia de los protocolos médico-sanitarios, en aras del respeto de la dignidad humana del paciente.

El concepto de dignidad humana que ha recogido la Corte Constitucional, únicamente se explica dentro del sistema axiológico de la Constitución y en función del mismo sistema. Así las cosas, la elevación a rango constitucional de la "libertad de elección de un plan de vida concreto en el marco de las condiciones sociales en las que el individuo se desarrolle" y de "la posibilidad real y efectiva de gozar de ciertos bienes y de ciertos servicios que le permiten a todo ser humano funcionar en la sociedad según sus especiales condiciones y calidades, bajo la lógica de la inclusión y de la posibilidad de desarrollar un papel activo en la sociedad", definen los contornos de lo que se considera esencial, inherente $y$, por lo mismo inalienable para la persona, razón por la cual se traduce en derechos subjetivos (entendidos como expectativas positivas (prestaciones) o negativas, cuyos contenidos esenciales están sustraídos de las mayorías transitorias. En este orden de ideas, será fundamental todo derecho constitucional que funcionalmente esté dirigido a lograr la dignidad humana y sea traducible en un 
derecho subjetivo ${ }^{24}$ (Corte Constitucional de Colombia, 2003, p. 1).

Además, la incorporación del daño punitivo en la doctrina y legislación colombiana, generaría beneficios para el potencial victimario prestador en salud, porque las empresas promotoras y prestadoras de salud, destinarían un rubro adicional de su presupuesto, para el entrenamiento del recurso humano y personal administrativo

$24 \quad$ Al respecto, continúa la sentencia: "Es decir, en la medida en que resulte necesario para lograr la libertad de elección de un plan de vida concreto y la posibilidad de funcionar en sociedad y desarrollar un papel activo en ella. Tal necesidad no está determinada de manera apriorística, sino que se define a partir de los consensos (dogmática del derecho constitucional) existentes sobre la naturaleza funcionalmente necesaria de cierta prestación o abstención (traducibilidad en derecho subjetivo), así como de las circunstancias particulares de cada caso (tópica). Así, por ejemplo, en la actualidad existe consenso en torno a la absoluta necesidad de que los procedimientos judiciales y administrativos estén fijados normativamente (principio de legalidad) y que prevean la posibilidad de controvertir pruebas, presentar las propias y de rebatir argumentos y ofrecer los propios (derecho de defensa), para que la persona pueda ser libre y activa en sociedad; mientras que serán las circunstancias concretas las que definan si una cirugía estética únicamente persigue intereses narcisistas o responden a una necesidad funcional, para que la persona pueda ser activa en sociedad (v. gr. alteraciones funcionales y dolor que exigen una reducción de senos). Resulta ejemplarizante la discusión en torno al reconocimiento de derechos fundamentales a personas jurídicas, en la cual el consenso logrado únicamente se explica por la necesidad de proteger elementos funcionalmente indispensables para la correcta operación jurídica de estas instituciones. [...] Lo anterior, debe precisarse, no implica que en sí mismo derechos constitucionales no tengan carácter fundamental. La existencia de consensos (en principio dogmática constitucional) en torno a la naturaleza fundamental de un derecho constitucional implica que prima facie dicho derecho se estima fundamental en sí mismo. Ello se explica por cuanto los consensos se apoyan en una concepción común de los valores fundantes de la sociedad y el sistema jurídico. Así, existe un consenso sobre el carácter fundamental del derecho a la vida, a la libertad y a la igualdad. Los consensos sobre la naturaleza fundamental de estos derechos claramente se explica por la imperiosa necesidad de proteger tales derechos a fin de que se pueda calificar de democracia constitucional y de Estado social de derecho el modelo colombiano. No sobra indicar que, en la actual concepción de dignidad humana, estos derechos son requisitos sine qua non para predicar el respeto por dicho valor" (Corte Constitucional de Colombia, 2003, p. 2). en salud. La capacitación generaría pericia y observancia de los protocolos médicos en los prestadores sanitarios, y su comportamiento mudaría, generando provechos para el paciente. En suma, la minimización del riesgo producida por la capacitación del recurso humano, además del juicio de reproche ejemplarizante, crea beneficios para el usuario en salud, pero también para el prestador médico.

\section{LAS FUNCIONES DE LA RESPONSABILIDAD CIVIL MÉDICO- SANITARIA Y LA APLICACIÓN DE LA TEORÍA DEL DAÑO PUNITIVO}

En el derecho de daños y concretamente el derecho de la responsabilidad médico-sanitaria, es improbable la tasación de perjuicios de manera anticipada, porque se desconoce la identificación concreta del paciente a quien se le causarán daños; igualmente son inciertos el monto de la indemnización a cargo del victimario, la existencia previa del hecho generador de culpa, la causa del evento adverso y se reitera, el importe a indemnizar por el prestador en salud legitimado por pasiva en el proceso judicial pertinente.

Por tal razón, el derecho de daños o también llamado derecho de la responsabilidad civil por daños o accidentes,

[...] desempeña un papel fundamental. En particular, el derecho de responsabilidad civil por daños se considera como un complemento al derecho contractual, asignando los derechos a quienes les asignan un uso más valioso, a cambio del cumplimiento efectivo de las contraprestaciones que se hubieran convenido e imputando las obligaciones a quienes puedan soportarlas con un menor costo (Infante, 2013).

Las víctimas de los eventos adversos causados en la relación médico/paciente, pueden iniciar acciones judiciales con el objetivo de que el operador adscrito a la rama judicial del poder público, ordene al prestador del servicio médico, el pago de una indemnización proporcional al 
perjuicio generado. No obstante, el valor de la indemnización puede ser insignificante ${ }^{25}$ para el condenado en el proceso, es decir, el prestador del servicio médico que produjo el siniestro o daño creador de perjuicios.

Por un lado, el derecho de daños se considera un complemento del derecho contractual, para el caso en estudio, el acto jurídico bilateral celebrado entre el prestador en salud y el paciente. Por otro, al no existir en la prestación del servicio médico y sanitario una compensación anticipada de perjuicios, el derecho de la responsabilidad derivada del daño producido al paciente, cumple con dos funciones esenciales: preventiva $y$ resarcitoria.

\section{FUNCIÓN PREVENTIVA O PROTECTORA}

La víctima del hecho médico-sanitario generador de un daño, puede demandar la indemnización de los perjuicios en la jurisdicción ordinaria civil o la jurisdicción contenciosa administrativa. La categoría jurisdicción representa el género y la especie está constituida por la jurisdicción civil cuando el demandado corresponde a un prestador en salud privado, y administrativa en el evento de ser el hospital o un servidor público el causante del daño; así las cosas, la civil, estatal, penal, entre otras, son las especies de jurisdicción (Pietro, 1964). Sin embargo, de acuerdo con lo señalado con anterioridad, existe la jurisdicción constitucional cuyo objetivo es el amparar los derechos del paciente.

La función preventiva busca producir incentivos en los prestadores del servicio en salud, con el objetivo de disuadir al recurso humano en salud y a los directivos de los operadores y prestadores sanitarios, para que modifiquen sus conductas dañosas. En conclusión, la función preventiva de la responsabilidad médica y sanitaria, ese dirige

25 De no imponerse una sanción ejemplarizante a través de una cuantía significativa, el prestador en salud, "preferiría seguir actuando, como lo venía haciendo, motivado por los beneficios que obtuvo o puede seguir obteniendo" (Zavala, 2009, p. 343). a "[...] desincentivar accidentes, o reducción de costos privados, es decir, internalizar externalidades para generar incentivos, a fin de que haya menos accidentes [...]"26 (Infante, 2013) o presencia de eventos adversos, ante todo en la población vulnerable.

Por ende, el hecho de lograr que el prestador en salud internalice o razone acerca de las externalidades o los riesgos que pueden exteriorizarse, hace que su comportamiento cambie y por consiguiente se produzca un beneficio para la víctima del daño galénico. Comportamiento que puede modificarse, con la aplicación del daño punitivo.

\section{FUNCIÓN RESARCITORIA, INDEMNIZATORIA O COMPENSATORIA}

La víctima del hecho médico generador de perjuicios materiales e inmateriales, tiene tres derechos fundamentales que deben ampararse. El primero, es el derecho a la verdad sobre los hechos que ocasionaron el daño y el derecho a conocer su estado de salud; el segundo, relacionado con el derecho a la justicia garantizando su acceso sin dilaciones injustificadas. Por último, la víctima

26 En este sentido, es importante indicar que "Para la jurisprudencia constitucional, cuando el goce efectivo de un derecho constitucional fundamental depende del desarrollo progresivo, "lo mínimo que debe hacer [la autoridad responsable] para proteger la prestación de carácter programático derivada de la dimensión positiva de [un derecho fundamental] en un Estado social de derecho y en una democracia participativa, es, precisamente, contar con un programa o con un plan encaminado a asegurar el goce efectivo de sus derechos' (Corte Constitucional de Colombia, 2002). Igualmente, la Corte Constitucional de Colombia señaló lo siguiente en relación con la protección de las personas con discapacidad: 'Si bien Transmilenio S. A. no puede de manera inmediata e instantánea, garantizar el acceso de Daniel Arturo Bermúdez Urrego al sistema de transporte sin tener que soportar cargas excesivas, lo mínimo que debe hacer para proteger la prestación de carácter programático derivada de la dimensión positiva de la libertad de locomoción en un Estado social de derecho y en una democracia participativa, es, precisamente, contar con un programa o con un plan encaminado a asegurar el goce efectivo de sus derechos, como de los demás discapacitados físicos'" (Corte Constitucional de Colombia, 2002). 
del daño tiene derecho a la reparación integral; derecho que debe garantizársele, cumpliendo de esta forma con la función resarcitoria de la responsabilidad médica señalada en este acápite. Para este efecto,

El legislador ha establecido como elementos que integran el concepto de reparación integral, no solo la indemnización pecuniaria fruto de la responsabilidad civil reconocida como consecuencia del daño causado por el delito, reparación en sentido lato, sino cualesquiera otras expresiones que contengan la verdad y la justicia, así como las actuaciones que de modo razonable reclame la víctima del sujeto penalmente responsable, en cuanto forma de cubrir el perjuicio moral y material que ha sufrido. En este sentido recuerda la Corte que la noción de reparación civil es independiente al proceso en el cual se obtenga (art. 16 de la ley 446 de 1998), razón por la cual los criterios que se apliquen deben ser homogéneos (Corte Constitucional de Colombia, 2009, p. 2).

Por consiguiente, la función resarcitoria garantiza a la víctima del hecho médico-sanitario generador de perjuicios, que los eventos adversos, sean compensados; daños causantes de lesiones materiales e inmateriales, representadas las últimas en el daño emergente y lucro cesante, y los perjuicios morales, fisiológicos a la vida de relación $y$ condiciones de existencia, en la actualidad denominados perjuicios a la salud, así como los perjuicios psicológicos, estéticos y la pérdida de la oportunidad del paciente, los últimos instituidos en especies del género extrapatrimoniales.

Al mismo tiempo, un evento adverso ${ }^{27}$ generador del daño puede estimarse como un intercambio

$27 \quad$ Es importante expresar lo siguiente: "El primer elemento que constituye la esencia del concepto de evento adverso es el daño en el paciente. No hay evento adverso sin daño. Este primer elemento es fácil de determinar cuando el daño es evidente, como en el caso de la muerte de una persona o de una incapacidad permanente mayor (daño cerebral, pérdida de un órgano o de una función corporal). Por supuesto, este tipo de daño es el más temido y, generalmente, el más fácil de identificar. Sin embargo, existe otro tipo de daño que es preciso contemplar cuando se analiza una situación clínica para enmarcarla como evento adverso" (Luengas, 2009, p. 6). de derechos entre el paciente y el prestador en salud; dicho intercambio es forzoso y a la vez involuntario, produciendo de esta manera "[...] costos externos y cuyas consecuencias pueden cuantificarse en dinero. De esto se deriva la necesidad de adoptar mecanismos que posibiliten la internalización de esos costos, para su integración al precio" 28 (Infante, 2013). En concordancia, el sistema o título de imputación aplicable en los procesos por responsabilidad médico-sanitaria, es el subjetivo fundamentado en la "culpa" del prestador en salud, donde no únicamente se debe demostrar por parte del paciente que se exteriorizó un riesgo, es decir, que ocurrió un siniestro médico.

En este tipo de procesos declarativos que buscan la verdad, la justicia y la reparación integral, se debe determinar el comportamiento del prestador en salud quien es sujeto pasivo en la demanda; análisis del comportamiento prudente, diligente u observante de los protocolos médicos, que permitan estudiar si el recurso en salud involucrado en el hecho dañoso, tuvo la posibilidad de prever los perjuicios ocasionados con su conducta. Por tanto, en el evento de presentarse una infección intrahospitalaria por ejemplo, el operador judicial debe estudiar no la actividad médica en sí, sino el comportamiento negligente o imprudente del prestador en salud causante del daño. La citada infección, se ha definido de la siguiente manera: Una infección contraída en el hospital por un paciente internado por una razón distinta de esa infección. Una infección que se presenta en

28 La autora indica que "En particular, las eficiencias están relacionadas con la minimización de los siguientes costos: 1) Los que se originan en la prevención de los daños; 2) Los costos sociales que emanan de los accidentes, $y$

3) Los que se originan en la instrumentación y administración del sistema legal de responsabilidad civil. [...] Con relación al tercer costo, es relevante mencionar aquí que el aparato de administración de justicia tiene que ser eficiente para que el sistema pueda funcionar. No obstante, contar con aparatos de justicia eficientes cuesta dinero, ya que es necesario dotarlos de recursos suficientes para colocarlos en situación de resolver correctamente los casos que se presentan. Por ejemplo, un sistema de culpa finalmente implica una mayor inversión en el aparato judicial, porque probar la culpa es más difícil que probar la simple causalidad" (Infante, 2013). 
un paciente internado en un hospital o en otro establecimiento de atención de salud en quien la infección no se había manifestado ni estaba en período de incubación en el momento del internado. Comprende las infecciones contraídas en el hospital, pero manifiestas después del alta hospitalaria y también las infecciones ocupacionales del personal del establecimiento (OMS, 2003, p 7).

El anterior, es un típico ejemplo de evento adverso. Sin embargo, en la práctica médica la mayoría de infecciones se remedia satisfactoriamente, sin que existan secuelas relevantes. En la actualidad, las flebitis o inflamaciones generadas por el uso de catéteres, la sobredosificación de algún tipo de medicamento que no origina hechos dañosos de tipo funcional, y los sangrados quirúrgicos irregulares, se solucionan rápidamente sin producir traumatismos. Los ejemplos que ya se señalaron, se catalogan como eventos adversos de tipo temporal, porque no crean daños graves al paciente ${ }^{29}$ (Luengas, 2009).

No obstante, existen eventos que lesionan de manera grave al paciente, exteriorizando un riesgo inminente para su integridad física y mental.

Existe otro tipo de evento adverso aún más complicado de identificar. Aquel en el que es difícil establecer un límite claro entre su origen en la atención en salud o su origen en la enfermedad de base. Un par de ejemplos nos ayudan a entender con mayor facilidad este tipo de casos. Supongamos a un recién nacido con un cuadro de incompatibilidad de grupo sanguíneo, que genera una icte-

29 Por el contrario, existen eventos adversos que pueden lesionar la vida e integridad física del paciente. Este es el caso: "Un paciente con un cáncer en un estadio avanzado cuyo pronóstico es muy reservado, y finalmente fallece. No es un evento adverso. Simplemente es la consecuencia de una patología de base para la cual la ciencia médica aún no cuenta con la tecnología necesaria para revertirla o modificar su curso natural; pero si añadimos que el paciente fue sometido a una quimioterapia con una dosificación subterapéutica de citostáticos, esto es claramente un evento adverso. El daño está en que se le quitaron sus pocas probabilidades de supervivencia" (Luengas, 2009, p. 7). ricia y durante la hospitalización sufre un cuadro de kernicterus. El cuadro clínico es claramente consecuencia de su patología de base; pero un kernicterus intrahospitalario, por definición, es un evento adverso. Es responsabilidad de la atención en salud modificar el curso natural de la enfermedad. De eso se trata la atención en salud, ¿no? Si no se le hizo un seguimiento adecuado a este neonato o no hubo una intervención oportuna (por ejemplo, una exsanguíneo transfusión), ¿qué sentido tiene la atención en salud? ${ }^{30}$ (Luengas, 2009, p. 7).

En conclusión, todo evento adverso generador de daños donde la causa del mismo le sea imputada al comportamiento del prestador en salud, debe repararse de modo integral. Así las cosas, pueden darse perjuicios morales sin la presencia de perjuicios patrimoniales, como en el caso del paciente que se niega a recibir unidades de sangre, porque sus convicciones religiosas no lo permiten. El hecho de contrariar la voluntad del paciente con mayoría de edad y que tenga pleno conocimiento de la situación médica en la que se encuentra, configura un indicio de atención insegura y ocasiona la presencia de un evento adverso productor de perjuicios inmateriales $y$ materiales.

$30 \quad$ Por su parte, el kernicterus "Es una afección neurológica poco común que ocurre en algunos recién nacidos con ictericia severa [...] Causas. El kernicterus es causado por niveles muy altos de bilirrubina, un pigmento amarillo que se crea en el cuerpo durante el reciclaje normal de los glóbulos rojos viejos. Los niveles altos de bilirrubina en el cuerpo pueden hacer que la piel luzca de color amarillo, lo cual se denomina ictericia. En algunos casos, cuando hay niveles sumamente altos de bilirrubina en el cuerpo o el bebé está extremadamente enfermo, la sustancia se movilizará por fuera de la sangre y se acumulará en el tejido cerebral. Esto puede llevar a complicaciones neurológicas serias, incluyendo daño en el cerebro e hipoacusia. El kernicterus normalmente se desarrolla en la primera semana de vida, pero puede observarse hasta la tercera semana. Los recién nacidos con enfermedad hemolítica del Rh que puede llevar a hidropesía fetal están en alto riesgo de presentar ictericia grave que conduce a esta afección. Sin embargo, el kernicterus se ha visto en bebés aparentemente saludables" (American Academy of Pediatrics, 2004, 2010). 
Gráfica 2. Calidad y la atención en salud

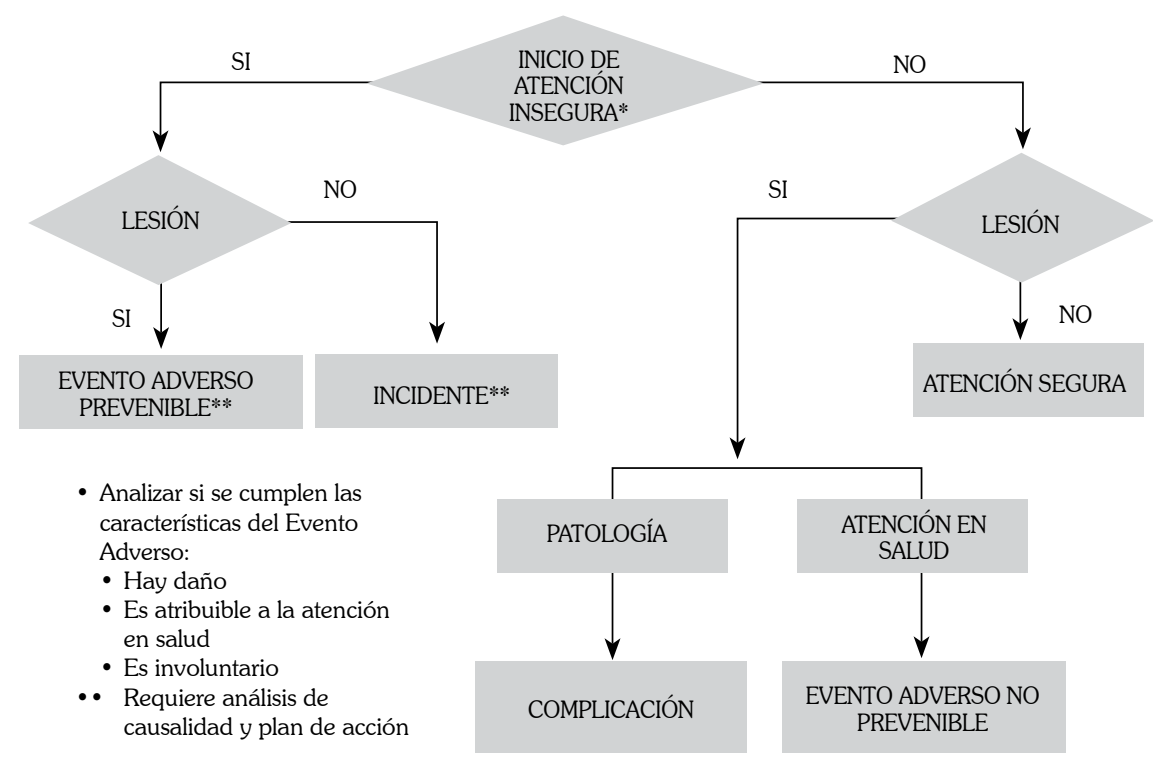

Fuente: Observatorio de Calidad de la Atención en Salud (s. f.).

Por lo tanto, el daño causado al paciente debe repararse y de acuerdo con lo ya expresado, dicha reparación integral es un derecho fundamental de la víctima que no se puede transgredir. Derecho que lo puede garantizar el derecho de daños y la aplicación de la teoría del daño punitivo o juicio de reproche ejemplarizante.

\section{CONCLUSIONES}

En el acto jurídico contractual celebrado entre el prestador sanitario y el paciente, se pueden presentar eventos adversos que generan perjuicios patrimoniales e inmateriales al usuario médico; estos eventos, pueden ser consecuencia de la negligencia por acción u omisión del prestador en salud, y para prevenir, sancionar o reparar los efectos negativos del hecho generador de culpa, se instituyen acciones constitucionales y legales. La acción de tutela, las acciones populares y de grupo buscan la protección de los derechos del paciente. Se identificó igualmente en la investigación, que la aplicación del derecho de daños sumado a la incorporación de la teoría de los daños punitivos, protegería los derechos humanos del usuario médico.

Se identificó en la investigación, que los eventos adversos pueden lesionar los derechos humanos y fundamentales del paciente; el daño producido por el prestador en salud, se puede generar como resultado de hechos jurídicos ilícitos causados con culpa o dolo.

Se encontró que al darse el evento adverso que perjudica los derechos humanos y fundamentales del paciente, se ordena por parte del juez el pago de la indemnización a la víctima. Dicho pago involucra la tasación de los daños materiales $e$ inmateriales que en oportunidades pueden ser insuficientes, por un lado, como juicio de reproche ejemplarizante y por otro, constituyen una indemnización, pero no integral de los perjuicios causados. Con el propósito de modificar el comportamiento del prestador sanitario, se propone la aplicación de los daños punitivos en Colombia. 


\section{REFERENCIAS}

Alcalá, C. (1947). Proceso, autocomposición y defensa. México D. F.: Universidad Autónoma de México (Unam).

Alexy, R. (2000). On the structure of legal principles. Ratio Iuris, 13 p. 3.

American Academy of Pediatrics. (2004). Subcommittee on hyperbilirubinemia management of hyperbilirubinemia in the newborn infant 35 or more weeks of gestation. Pediatrics. pp 297316. Recuperado de http://stlukespmc.adam. $\mathrm{com} /$ content. aspx?productld $=118 \& \mathrm{pid}=5 \& \mathrm{~g}$ $\mathrm{id}=007309$.

American Academy of Pediatrics. (2010). Committee on Fetus and Newborn. Hospital Stay for Healthy term Newborns. Pediatrics. pp. 125 - 405 Recuperado de http://stlukespmc.adam. $\mathrm{com} /$ content. aspx?productld $=118 \& \mathrm{pid}=5 \& \mathrm{~g}$ $\mathrm{id}=007309$.

Buitrago, J. (2007). El daño punitivo en la responsabilidad civil. Bogotá: TM. Universidad Externado de Colombia, Litografía Moderna Digital.

Cianciardo, J. (2011). Principios y reglas: una aproximación desde los criterios de distinción. Boletín Mexicano de Derecho Comparado, 108. México D. F.: Instituto de Investigaciones Jurídicas Unam.

Colombo, J. (2002). Funciones del derecho procesal constitucional. Ius et Praxis, 8. Recuperado de http://www.scielo.cl/scielo.php?script=sci_art text\&pid=S0718-00122002000200002.

Congreso de la República de Colombia. (2007). Ley 1122/2007. Diario Oficial 46506 de enero 09 de 2007. Reglamentada parcialmente por el decreto nacional 313/2008, modificada por el art. 36, decreto nacional 126/2010, en lo relativo a las multas por la cual se hacen algunas modificaciones en el Sistema General de Seguridad Social en Salud y se dictan otras disposiciones.
Corte Constitucional de Colombia. (1993). Sentencia T-597/1993. M. P. Eduardo Cifuentes Muñoz.

Corte Constitucional de Colombia. (2000). Sentencia T-1204/2000. M. P. Alejandro Martínez Caballero.

Corte Constitucional de Colombia. (2002). Sentencia C-228/2002. M. P. Manuel José Cepeda, Eduardo Montealegre Lynett.

Corte Constitucional de Colombia. (2002). Sentencia T-571/2002. M. P. Jaime Córdoba Triviño.

Corte Constitucional de Colombia. (2003). Sentencia T-227/2003. M. P. Eduardo Montealegre Lynett.

Corte Constitucional de Colombia. (2004). Sentencia expedientes T-862549 del 4 de agosto de 2004. M. P. Álvaro Tafur Galvis.

Corte Constitucional de Colombia. (2005). Sentencia T-1022/2005. M. P. Manuel José Cepeda Espinosa.

Corte Constitucional de Colombia. (2006). Sentencia T-557/2006. M. P. Manuel José Cepeda Espinosa.

Corte Constitucional de Colombia. (2006). Sentencia T-829/2006. M. P. Manuel José Cepeda Espinosa.

Corte Constitucional de Colombia. (2007). Sentencia T-565/2007. M. P. Clara Inés Vargas Hernández.

Corte Constitucional de Colombia. (2007). Sentencia T-788/2007. M. P. Rodrigo Escobar Gil.

Corte Constitucional de Colombia. (2007). Sentencia T-1079/2007. M. P. Humberto Antonio Sierra Porto.

Corte Constitucional de Colombia. (2007). Sentencia T-148/2007. M. P. Humberto Antonio Sierra Porto. 
Corte Constitucional de Colombia. (2008). Sentencia T-760/2008. M. P. Manuel José Cepeda Espinosa.

Corte Constitucional de Colombia. (2009). Sentencia C-409/2009. M. P. Juan Carlos Henao Pérez.

Corte Constitucional de Colombia. (2011). Expediente D-8422 de 31 de agosto de 2011. M. P. Jorge Iván Palacio.

Couture, E. (1948). Estudios de derecho procesal civil (3 $3^{\text {er }}$ tomo). Buenos Aires: Ediar.

Defensoría del Pueblo. (2007). La tutela y el derecho a la salud. Período 2003-2005. Bogotá: Defensoría del Pueblo.

Escardó, F. (1954). El alma del médico. Córdoba: Alessandri.

Fix-Zamudio, H. (1964). El juicio de Amparo. México D. F.: Porrúa.

Fix-Zamudio, H. (1984). La aportación de Piero Calamandrei al derecho procesal constitucional. Revista de la Facultad de Derecho de México, 23, julio-septiembre. pp. 143-159.

Galindo, J. (2011). La salud y su aseguramiento en Argentina, Chile, Colombia y España. Madrid: Fundación Mapfre.

García, D. (1971). El hábeas corpus en el Perú. Lima: Ediciones Universidad de San Marcos.

González, J. (1980). Derecho procesal constitucional. Madrid: Civitas.

Gozaíni, O. (1988). Introducción al nuevo derecho procesal. Buenos Aires: Ediar.

Infante, M. (2013). Funciones económicas del derecho de responsabilidad civil. Gaceta Judicial. Recuperado de http://www.gacetajudicial. com.do/analisis-economico/analisis-economicoresponsabilidad2.html
Lombana, J. (2007). Derecho penal y responsabilidad médica ( $3^{\mathrm{a}}$ ed.). Medellín: Diké.

López, J. (2008). El derecho a la salud como derecho fundamental. Revista Vía Salud. Volumen 43. pp. 34 - 36.

López, J. (2013). La responsabilidad médica del Estado o de los prestadores en salud derivada de prótesis mamarias defectuosas. Revista Prolegómenos. Derechos y Valores. Volumen XVI - N ${ }^{\circ}$ 31. pp. 131 - 153.

López, M. (2009). Elementos de la responsabilidad civil: colección internacional. Bogotá: Diké.

Loriano, A. (2009). La enseñanza del derecho procesal constitucional. Experiencias y perspectivas. Academia. Revista sobre Enseñanza del Derecho, 7(13), 1667-4154.

Luengas, S. (2009). Seguridad del paciente: conceptos y análisis de eventos adversos. Centro de Gestión Hospitalaria, Vía Salud, p. 48.

Ministerio de la Protección Social. (2006). Resolución 1446. Por la cual se define el Sistema de Información para la Calidad y se adoptan los indicadores de monitoría del Sistema Obligatorio de Garantía de Calidad de la Atención en Salud.

Ministerio de Salud y Protección Social de Colombia. (s. f.). Salud pública. Recuperado de http://www.minsalud.gov.co/salud/Paginas/saludpublica.aspx

Olano, H. (2006). Constitución Política de Colombia ( $7^{\mathrm{a}}$ ed.). Bogotá: Doctrina y Ley.

Organización de las Naciones Unidas. (1945). Las Naciones Unidas. Recuperado de http:// www.un.org/es/aboutun/

Organización de las Naciones Unidas (ONU). (1985). Oficina del alto comisionado de las Naciones Unidas para los Derechos Humanos. Declaración sobre los principios fundamentales de justicia para las víctimas de delitos y del abuso 
de poder; adoptada por la Asamblea General en su resolución 40/34.

Organización Mundial de la Salud. (2003). Prevención de las infecciones nosocomiales. Guía práctica ( $2^{\mathrm{a}}$ ed.). Recuperado de http://www. who.int/csr/resources/publications/drugresist/ PISpanish3.pdf

Observatorio de Calidad de la Atención en Salud. (s. f.). Qué es. Recuperado de http://201.234.78.38/ocs/public/seg_paciente/ Default.aspx?pageNum = 1 el 03/02/2014

Pietro, L. (1964). Derecho procesal civil. Revista de Derecho Privado, p 1.

San Juan, N. (2008). Comunicación oral. Director Departamento de Microbiología, Parasitología e Inmunología. Universidad de Buenos Aires, Argentina. Buenos Aires: Facultad de Medicina. Recuperado de http://www.fmed.uba.ar/depto/ microbiologia/eljuhi.pdf
Senado de la Nación Argentina. (2008). Ley de Defensa del Consumidor 24.240 reformada por la 26.361, artículo 2. Boletín Oficial, 31378, abril 7.

Seoane, J. A. (2005). Un código ideal y procedimental de la razón práctica: la teoría de la argumentación jurídica de Robert Alexy. Universidad da Coruña. pp. 105 - 196.

Terragani, M. (2009). Dolo eventual y culpa consciente: adecuación de la conducta a los respectivos tipos penales. Buenos Aires: Rubinzal Culzoni Editores.

Uprimny, R. (2014). Salud y patentes. Periódico el Espectador. Publicación 27 de enero de 2014.

Villalobos, I. (2002). La tentativa y el dolo. Caracas: Editorial Jurídica Bolivariana.

Zavala, M. (2009). Resarcimiento del daño moral. Buenos Aires: Astrea. Edición 1. 